\title{
Evaluation of the environmental and social sustainability policy of a mass tourism resort: A narrative account
}

\begin{abstract}
Authors:
Isabel Swart ${ }^{1}$

André C. Horn ${ }^{2}$

Affiliations:

${ }^{1}$ Centre for Environmental

Studies, University of

Pretoria, South Africa

${ }^{2}$ Department of Geography,

Geo-Informatics and

Meteorology, University of

Pretoria, South Africa

Note:

The article is based on a

M.Sc. mini-dissertation by

Isabel Swart and supervised

by Prof. Dr André C. Horn.

Correspondence to:

Isabel Swart

Email:

isa.swart@za.suninternational.

com

Postal address:

PO Box 777, Temba 0407,

South Africa

\section{Dates:}

Received: 04 May 2012

Accepted: 06 June 2012

Published: 14 Sept. 2012

How to cite this article:

Swart, I. \& Horn, A.C.,

2012, 'Evaluation of the environmental and social sustainability policy of a mass tourism resort: A narrative account', HTS Teologiese Studies/Theological Studies 68(1), Art. \#1264, 7 pages. http://dx.doi.org/10.4102/ hts.v68i1.1264
\end{abstract}

C 2012. The Authors. Licensee: AOSIS OpenJournals. This work is licensed under the Creative Commons Attribution License.
The recordation of the life stories of individuals residing in the community of Ledig, who have been dependent on the Sun City Resort situated in the Pilanesberg area in the North West Province of South Africa for their quality of life for more than 20 years, provided the basis for the evaluation of the environmental and social sustainability of this micro-cosmos on a multidisciplinary level. This study focused on the hermeneutical arch of narrative theory within the framework of human geography and sustainability science. The natural environment was evaluated for the role it plays in the sustainability of the livelihoods of the Ledig community members as well as the institutional life of the Sun City Resort. The results of this study suggested that the environmental policy for the Sun City Resort, formalised in 2004, has been guiding the Sun City Resort to contribute positively to the sustainability of the area. The study also demonstrated that a focus on the next generation of potential employees and the environmental education of all the communities were crucial to ensure the resilience of the social and ecological capacity of the area.

\section{Introduction}

\section{Focus}

The formulation of an Environmental Policy for the Sun City Resort in 2004 was guided by the Responsible Tourism Development Provisional Guidelines for South Africa (Department of Environmental Affairs and Tourism [DEAT] 2002). It introduced the process of formalising the Resort's commitment to be internationally recognised as a sustainable tourism destination. This policy is evaluated in this study for its contribution to the social and environmental sustainability of the Resort and its most adjacent community, the people of Ledig settlement.

\section{Background}

The Pilanesberg complex is an area where, after massive volcanic upheaval some 1300 million years ago, a natural sanctuary was created surrounded by rings of mountains. Over time the area was occupied by Stone Age and Iron Age people such as the Bakubung, before White people settled here in the mid-1800s. The volcanic rock formations in the Pilanesberg contain large amounts of fluoride and taken up in ground water, cause dental fluorosis. Since the early 1800s the district was predominantly used for cattle farming and dry land crops resulting in land degradation (North West Parks Board 1997). In the latter 20th century the area became part of the Bophuthatswana homeland that became 'independent' from South Africa in 1978.

The proclamation of the Pilanesberg National Park (PNP) of 55000 ha in 1979 and the subsequent 'Operation Genesis' project relocating humans and stocking the park with wild animals had a dramatic impact on the area. Moreover, the Sun City Resort of about 3000 ha, on the border of the park some $187 \mathrm{~km}$ from Johannesburg, set a new benchmark for resorts (cf. Ringdahl 2003) and included one of the first licensed casinos in southern Africa when it opened its doors on 07 December 1979.

'Too garish to ignore, too fantastic to be real', Sun City (Figure 1) was hijacked as a political symbol from the start. Operating under a different set of rules in a nominally sovereign country, Sun City, built in an 'independent' Black state within South Africa and became the symbol of the excesses of South Africa during the apartheid years. Sun City was seen as a positive affirmation of South Africa's future and the role it could play in world tourism (South African History online 2011).

Due to the Resort's huge success initially, with more than 3 million visitors per annum, it was extended in 1990 by the construction of the 1 billion rand Palace of the Lost City. One hundred 
sub-contractors with almost 5000 people worked on the project at the peak of construction. Many of these workers were either from local villages or they were housed in kampongs or villages adjacent to the Resort. An economy of informal businesses arose overnight to supply food and other necessities to these workers.

A manmade botanical jungle of twenty-five hectares - the gardens of the Lost City - contains more than one million six hundred thousand plants, trees and shrubs. Various habitats have been created using over three thousand different species of plants of which $80 \%$ are indigenous. These gardens were created in less than 18 months and the landscape company coined the phrase 'we went to hell and back to create heaven'.
The visual, ecological and social impact of the Resort was observed by an unidentified author:

The scrawny veld, home of the Ba-Tswana, broken here and there by goats, chickens and tin-shanty settlements, suddenly dips, rises, and leads you into the lush green valley with the glittering, multi-turreted temple in its embrace. (South African History online 2011)

The impact of Sun City on the region is not only observable in the environmental contrast between the Resort and surrounding areas, but also in its contribution to the development of local communities.

Almost all sectors of the economy benefited from the construction of the Resort, as well as subsequent tourism in the

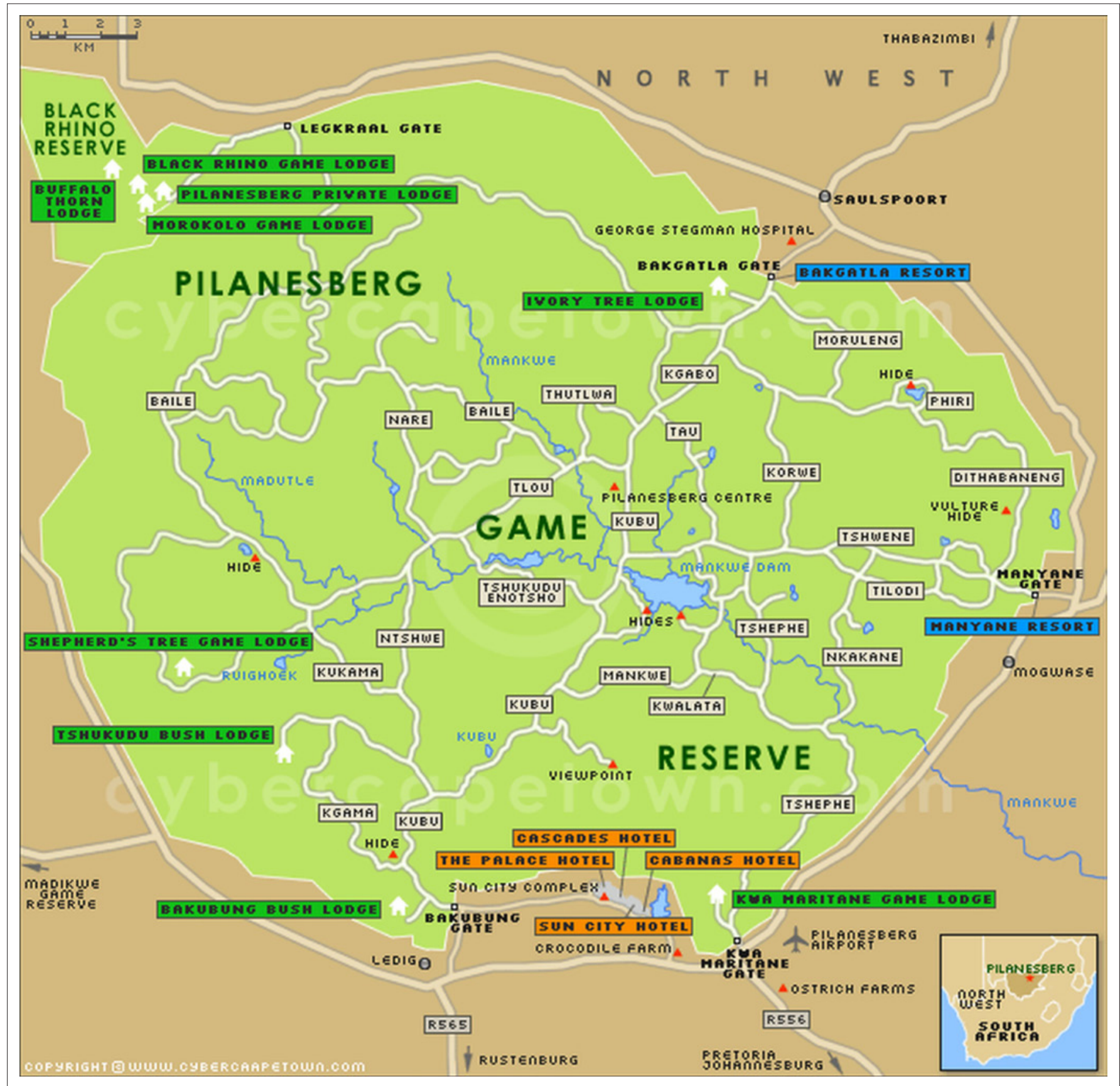

Source: Cyber Cape Town, n.d.,'Map of Pilanesberg Game Reserve, Map of Sun City', viewed 13 August 2012, from http://cybercapetown.com/Maps/PilanesbergGameReserve/ FIGURE 1: Location of the Sun City Resort. 
area. The community of Ledig, for example, prospered due to jobs that were created; the mushrooming of taverns, shebeens, car washes, shops, taxi services, schools, early learning centres and clinics was inevitable. The community also benefited hugely from the building of water and electricity reticulation systems and roads constructed by the Resort.

Today, Sun City is the largest employer in the area (apart from the increasing number of platinum and chrome mines on its periphery). According to Spencely and Seif (2003), $66 \%$ of those employed by Sun City come from within a $20 \mathrm{~km}$ radius of the Resort. This holds true in 2011 for $93.82 \%$ of those employed at the Resort with $9.77 \%$ of total staff currently residing in Ledig. In 2003 the estimated count for regular employees were 1600 and currently the number is 1361, whilst the casual employees number more or less 4000. An effective Corporate Social Investment (CSI) programme has enhanced the lives of local communities for many years. The Sun City Resort allocates $1 \%$ of profit after tax to community development programmes and $2 \%$ to enterprise development. Self-sustainability is the main objective to enhance economic growth, alleviate poverty and uplift communities. To date, the Resort has financed R25 million of local infrastructure projects such as the building and furnishing of classrooms, early learning centres, clinics and more. As young people are the economically active population of any country, they have an important role to play in the development and improvement of the socioeconomy thereof. The modern challenges that the youth are facing are those of teenage pregnancy, HIV and AIDS and the lack of access to formal education (see Ncube in Swart 2011a).

\section{Trends}

Research into the economic and environmental impact of tourism is abundant, but finding material on its envirosocio-cultural impact is more challenging (see Pandey et al. 1995:2; Brida \& Zafta 2010:221). The use of qualitative and quantitative methodologies for the assessment of the impact of tourism on community development and sustainable livelihoods has been emerging since the mid 2000s (see Simpson 2007; Tao \& Wall 2008). Sustainable livelihoods is a people-centred paradigm and procedures usually involve an assessment of community activities, assets, capabilities, adaptive strategies and technologies, with emphasis on inherent capacities and local knowledge systems with no integration of the environmental aspect. A 2009 analysis of studies published in the Journal of Sustainable Tourism (see Lu \& Nepal 2009) reveals amongst others, that the majority of the papers only emphasise a single perspective, however there is an increasing trend toward providing integrated and synthesised views. A rise in the number of studies on collaboration and cultural sustainability and a drop in economics, environmental assessment and marketing are other trends observed. In addition, the definition of sustainable tourism has evolved to the understanding of it being a goal to be achieved rather than a type of tourism, and that even mass tourism destinations can be sustainable (see Lu \& Nepal 2009). Moreover, Lu and Nepal highlight the lack of interdisciplinary studies, particularly between social science and others.

\section{Objectives}

The Pilanesberg area is rich in minerals and platinum, and chrome mines are approaching the borders of the Resort and the park. In recent times the key factors for the sustainability of the Sun City-Pilanesberg-Ledig complex were the preservation of the social and ecological capacity of the area. In this study, the policy that guides the dynamics between the Resort, the adjacent community of Ledig, and the natural environment is evaluated for the role it plays in the sustainability of the livelihoods of community members as well as the institutional life of the Resort.

\section{Approach}

The concepts of Structuration Theory initiated by Anthony Giddens (1984) and the conceptual framework of Resilience of Social-Ecological Systems (SES) as presented by C.S. Holling (2001) provide a theoretical basis for the research on sustainability, whilst Paul Ricoeur's (1992) concept of the hermeneutical arch of Narrative Theory was utilised as reporting model. For further elaboration on these constructs refer to Swart (2011b) as well as the original authors.

Against the above background life history research became a valuable tool for qualitative recordation. Our aim was to capture the richness of the experiences of seven of the more than four hundred staff members known as the 20-30 year club based on their years of service to the Sun City Resort and the fact that they reside in the Ledig community.

\section{Research method, design, procedure and analysis}

The research methodology for the constructions of the life stories was chosen to look at the lives of people, the institutional life of Sun City as organisation, and to portray the social and environmental impact of this mega tourist destination on the most adjacent local community of Ledig. The necessary coherence between the methodological approach and the theoretical intentions of the research process was thoroughly considered and the interviews were a combination of discussions and critical conversations as a data production strategy (Pillay in Dunpath \& Samuel 2009). Interviews served the purpose of delving beneath statistically driven generalisations; they potentially validate the innate knowledge of ordinary people - and specifically women who are liable to be omitted from many research projects (cf. Fraser 2004:184). The methodological guidelines used in this study are a hybrid between that of Barnard (1984) and Fraser (2004), thus keeping in mind, the reconstructed regional approach and narrative research considerations. It also integrates insights of the author as the process developed.

Interviewees were selected from the 20-30 year club as this group represents the history of the Resort and its most adjacent community. An attempt was made to interview at least three woman and three men residing in Ledig with different combinations of having completed the Sun City's Kundiza Environmental Training Program or still having to complete it. 
Data capturing took into account that (1) the study was organised around a specific theme and was to capture the character of the area and avoid the self-evident, (2) time was an essential element of the empirical reality and none of the past, present or future had to be disregarded, (3) the frontier of human-environment relations had to be explored, (4) the authors had inter-disciplinary guidance based on a common interest in the area and (5) the authors did thorough preparation prior to interviews by studying the sociohistorical context of the participants' lives.

Specific guidelines were followed during the interviews:

1. A climate of trust already existed between the interviewees and the first author who personally conducted the interviews.

2. Sensitivity was shown for the venue and time frames most comfortable for the interviewees.

3. The researchers' investment in the research was made known to the interviewees and the process was explained.

4. All interviewees signed a consent form that included their name, ID number, home address and telephone number as well as an undertaking by the researchers to protect the identity of the participants.

5. Guideline questions were compiled to ensure coherence with the theoretical outcome of the study (see Swart 2011b).

6. Stories were left to unfold and the interviewer accommodated the different styles of each interviewee (however a concerted effort was made to ensure all guideline questions were addressed).

7. Some of the interpretations made by the interviewer were shared with interviewees and some critical discussions were entered into subsequently.

8. When interviewees invited response from the interviewer on statements they made, a cognitive effort was made to encourage without imparting judgement.

9. A journal was kept in which the interviewer noted answers to questions posed, critical discussions as well as emotions felt by both interviewer and interviewee.

In the analysis phase material was transcribed with limited 'cleaning up' of the research journal recordation. No chronology was forced either to the list of questions or the dates of events. Each interviewee received a written copy of their stories and was requested to check the detail (especially dates) and sign the document as proof of their acceptance

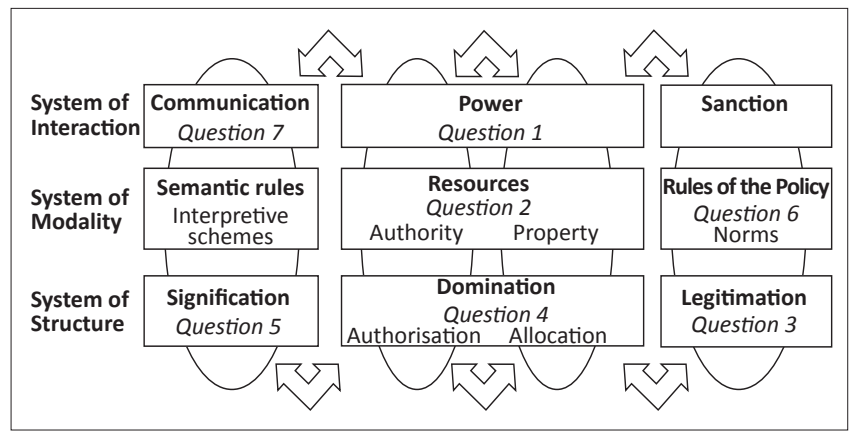

Source: Swart, 1., 2011b, 'Evaluation of the Environmental and Social Sustainability Policy of the Sun City Resort: A Narrative Account', mini-thesis, Centre for Environmental Studies (CFES), University of Pretoria

FIGURE 2: The Stratification Model of Structure applied to the study. that it was factually correct. In the case where not all the questions were addressed during the first interview, a second interview was requested or it was left unaddressed if not significant. All names were changed for the sake of privacy prior to taking up the stories in the dissertation.

Giddens's (1984) stratification model of structure is a representation of the interconnectivity of the everyday faceto-face micro world of interactions in the daily private and institutional lives of the human agents and the structures they operate in. The modalities represent the interpretative guidelines or paradigms that are subject to change as they serve as the representation of the collective consciousness that has developed over the years. In this study, the stories of participants were interpreted according to an adaptation of this model along the lines drawn by Gregory (see Cloke, Philo \& Sadler 1991), and for easy reference some information was tabulated as a summary (see Figure 2).

\section{Results}

The configuration of the life stories conveys the dynamics of the behaviour and interactions, the social constructs, cultural understandings and choices people make which supplies a basis for the evaluation of environmental and socio-cultural sustainability that follows in the refiguration or discussion. Refer to Swart (2011b) for the narrations of the seven participants and the tabular presentation of the data.

In order to highlight some of the pertinent issues presented in the narrations a linear methodology of data presentation, based on the following seven questions was used to capitalise on the life story genre promoting methodological pluralism:

1. Did Sun City as employer empower personal, financial and knowledge capacity building for the narrators?

2. What personal and social paradigms did the capacity building and racial integration create?

3. Do current Corporate Social Investment activities build capacity that enable sustainability of the Resort and its communities?

4. What are the challenges to social resilience in Ledig?

5. Does social capacity building contribute to the institutional capacity of Sun City?

6. To what extend has the Environmental Management System been taken on board as a social norm?

7. Could environmental capacity be improved through awareness creation and training?

\section{Discussion}

The discussion of successes, shortcomings and challenges in terms of environmental and social sustainability of Sun City as a tourism destination is based on the seven key questions posed. Some aspects confirmed by the narratives may be contributing or challenging the enviro-socio-cultural sustainability of the area are presented below:

1. Sun City as employer has empowered personal, social, financial and knowledge capacity building for the narrators. The 20-30 year club generation has been the main beneficiaries of the establishment of the Resort. It not only ensured financial income and personal development but also a sense of honour, pride and dignity: 
Jane: 'If it was not for Sun City I will not be Jane. Working at Sun City was a very glamorous option in 1984. I felt like a top class person when amongst other people ...'

Lizzie: 'Sun City was like gold. When you said you worked at Sun City people would respect you and they would know you are very rich. Now 25 years later the glamour and respect is still there.'

Mary: 'Sun City is committed to developing its people; different courses are available at the Training Centre and jobs are advertised if people want to move around.'

2. Those who took the opportunities have been strengthened with knowledge and skills that placed them in a position of power and increased resilience, both financially (owning their own properties, supporting extended families, sending children to school some up to tertiary level, comfortable with retirement plans) and as having authority (leaders in their community and advancement in managerial positions):

Ruth: 'Ledig peoples' lives are in Sun City and without Sun City most people in Ledig would not have a life. If not for Sun City were would Ruth be?'

Michael: 'If I stayed in Carletonville I would have died a long time ago as life there is corrupt and violent. We lived like gangsters and street kids.'

3. Social capacity improvement through Corporate Social Investment programmes leading to enhanced community identity and well-being was confirmed by most of the participants. They are aware of schools built and other activities especially assistance to AIDS patients and orphans:

Martha: 'Sun City has changed the culture of Ledig through developing schools which means their children do not have to travel far to attend school and kids from other communities are now also attending these schools.'

Ruth: 'Sun City made a huge difference for small kids looking after themselves in Lerome and Mabela Pudi.'

4. The identified challenges to the social resilience in Ledig have been that of crime, under-aged drinking, drug abuse and teenage pregnancies, escalating the AIDS pandemic and the abandonment of education opportunities. The Tribal Council corruption resulted in a disparity in which challenges such as the lack of extramural activities, sports grounds, running water and maintained access roads were not addressed by them. Although any CSI intervention addresses poverty and thus impacts the business, a deeper understanding of where the biggest return in terms of sustainability would be, has been made clear through this study. The respondents agree that the community, the Tribal Council and the Sun City Resort should take hands in addressing these challenges:
Petrus: 'The Tribal Council should take responsibility and go outside for sponsorships, am sure Sun City will help if it is for the kids.'

Lizzie: 'The kids in Ledig are terrible; the boys sniff glue, do drugs and have babies while they are still at school.'

5. Does social capacity building contribute to the institutional capacity of Sun City? The expectations of the present generation of youth regarding earning capacity are probably much higher than those of the previous generation, and the Resort is for them not a lucrative employer. There is concern that the new generation will experience a stagnant quality of life, thus nondevelopment with non-material economic growth due to the employment bottleneck and the service-based nature of the Resort, negatively influencing the institutional capacity of the Resort:

Lizzie: 'To get work at Sun City you need grade 12 . Kids whose parents died of AIDS do not have that as their grandparents cannot send them to school for higher education.'

Ruth: 'Sun City is Ledig's mine, but maybe not for the younger generation? They just work for a while and then go somewhere else. Are they looking for more money.'

There is a bottleneck when coming to opportunities for the youth of Ledig to find work at the Sun City Resort. As the 20-30 year club grows (at the time of this study 400 of the 700 permanent staff members have been working at the Resort for longer than 20 years) and ages, the availability of suitable candidates from the closest community might be diminishing due to school dropouts, teenage pregnancy, HIV and AIDS and in general the youth just losing hope for a better life. In another 5-15 years the current 20-30 year club staff will be retiring. Sufficient contingency plans should be put in place to ensure that there are 400 trained people to fill this gap over the next 15 years.

6. The Kundiza training programme, as a system of interaction within the structure, is an effective way of getting sustainability issues to become norms. It leads to empowerment that enables the sanctioning of the policy statements. It is apparent that in the workplace environmentally friendly thinking is becoming part of the interpretative schemes through informal, on the job training and social pressure for all to make the paradigm shift:

Lizzie: '... people are telling each other to switch off the equipment not in use and not even leave it on standby.'

Jane: 'Kundiza is the best course ever, it teaches you things you can take everywhere and everyone says so.'

It also became clear that the norms of health and safety were adopted successfully by the narrators and they are all aware of the efforts by the Resort to ensure safe working conditions for all staff: 
Lizzie: 'Sun City is a very safe working environment more (so) than other places; staff is being send for training and H\&S officers are appointed. The fire station is also well prepared.'

7. The Resort contributes to the ecological sustainability of the area by reducing its impact on the local environment through reduction in water consumption including grey water irrigation from its waste water treatment works as well as energy saving practises. Responsible waste management through improved recycling, reduction of littering and disposal on their own licensed landfill site improves the ecological capacity of the area as it ensures maintenance of its natural condition and subsequent ability to produce ecological services:

Lizzie: '... waste is well managed and the Resort is much cleaner. However, more people need to know about separation at source (s@s), especially contractors.'

Jane: 'Everyone tries to save water. I ensure that dripping taps in rooms are reported and staff members know not to waste water when cleaning and by closing taps.'

\section{Recommendations}

The following recommendations for the adjustments of the policy of the Sun City Resort and suggestions for future developments were made:

1. The policy should be amended to include the health, safety and quality activities already established on the Resort. This will be in line with the Global Sustainable Tourism Council (GSTC) Guidelines for a long-term sustainability management system (Global Sustainable Tourism Council 2011).

2. The current Kundiza training programme should become compulsory for all staff and it should be ensured that all attendees know the vision and the sequence moves. Focus on Resort-specific practises and the role each staff member can play is imperative. All new staff members should attend the training prior to being lowed to be operationally active. Equally, all business partner and concessionaires' staff should be subjected to the same norm.

3. On the job training sessions should be expanded to enhance the learning that takes place through Kundiza training intervention. A toolbox of short tailor-made training interventions should be developed and formalised for roll out to all departments. The consistent recordation of these interventions should be made to enable quantitative evaluation of numbers reached and progress made in turning sustainability thinking into the norm of the society at the Resort.

4. Awareness creation should include dissemination of information on the Sun City gardens and the Fable of the Lost City. The guest offering at the Palace could be greatly enhanced by showcasing the Fable through live theatre, and actors dressed according to a theme should become a daily part of the operations.
5. Contractors and business partner staff should undergo a short induction on environmental and safety norms prior to receiving access to the Resort.

6. In order to give effect to the policy, training and awareness activities should be expanded to the Ledig community. A more sustainable option should also be considered; the building of a 'sustainability centre' at the Resort would create the infrastructure for hosting schools, community groups and local and international visitors. Such a facility could become the centre of activity of the environmental and corporate social investment departments, housing not only the staff but also creating display facilities to communicate the 30-year history of the Resort.

7. The Resort should expand and strengthen its corporate social responsibility efforts through forging partnership and strategic alliances with existing social welfare structures and non-profit organisations. This would ensure that funds reach the communities directly for optimum effect while the administrative burden is diverted through the accountability taken by these structures.

8. AIDS orphans in need of homes, clothes and food are a significant challenge in the Ledig community and should receive special attention. Options include a community drive to identify and record affected children, assistance to the Tribal Council to supply housing and set up of a feeding and clothing scheme through donor funding, the organisation of therapeutic services, and the recruitment, training and parental skills development for foster parents can also be addressed by professional services.

9. Addressing the alcohol and drug dependency challenges in the community could be initiated through the identification of children who express a need for assistance. These cases could then be referred to rehabilitation facilities and assisted to complete the programmes with donor money.

10.Lastly, strategically designed vocational training and life skills development programmes to the youth to cater for the requirements of the economy should be supported by

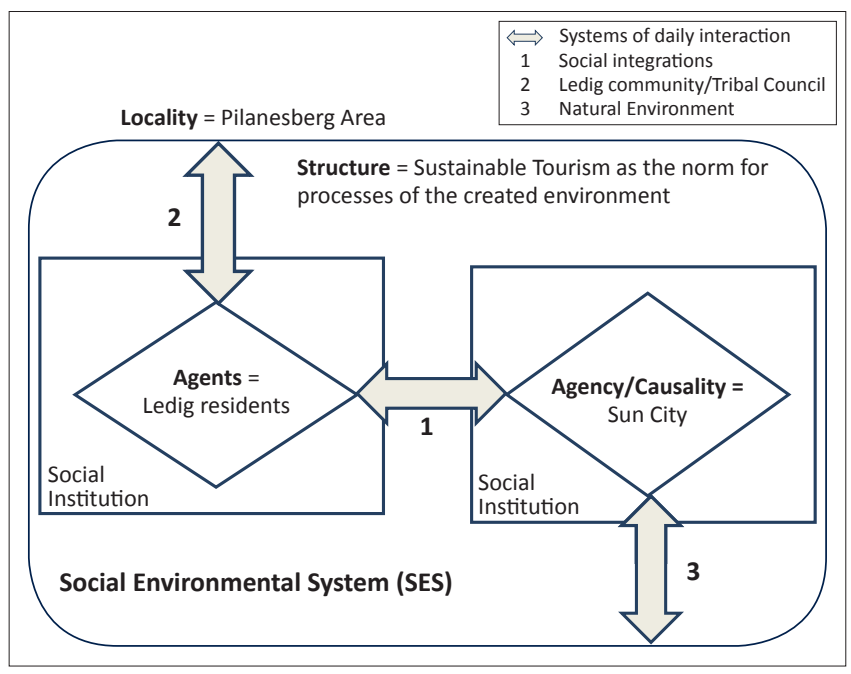

Source: Swart, I., 2011b, 'Evaluation of the Environmental and Social Sustainability Policy of the Sun City Resort: A Narrative Account', mini-thesis, Centre for Environmental Studies (CFES), University of Pretoria

FIGURE 3: A model of the structure of the Sun City-Pilanesberg-Ledig complex. 
the Resort as the resilience and capacity of the young people of the Ledig community is crucial to the sustainability of both the Resort and its adjacent community.

The above recommendations should be seen within the wider context of the individual and collaborated impact of the Sun City Resort, the Pilanesberg National Park, and the Ledig community on the structure of the larger complex (Figure 3).

The duality of influence between structure and agency is clearly demonstrated in Figure 3 when the concept of sustainable tourism requirements is added. Social integration of members of the Ledig community and the non-local staff and guests at Sun City Resort; the interaction of the community and the Resort have on the natural environment, represents the symbiotic relationships in this Social Environmental System (SES).

\section{Conclusion}

The primary objective of this study was to make a contribution to the scientific body of information regarding enviro-sociocultural sustainability in the tourism industry. The study demonstrated the contribution of an approach based on the hermeneutical arch of narrative theory within the framework of structure-agency interaction and sustainability science on sustainability in a mass tourism context.

The study was based on the life histories of long-term employees of the Sun City mass-tourism resort in South Africa and how they have been influenced by the environmental and social policy of the Sun City Resort. In the interpretation an attempt was made to understand, through re-living the stories - based on the interviewer's subjective involvement with the research question - to specifically be able to critically evaluate the extent to which the 2004 Environmental Policy has been taken on board or 'lived' by the interviewees, as this would be an indication of how the elements of sustainability have been integrated into the structure and social fabric of the institutions at the Resort and the Ledig community and where shortcomings exist.

The outcomes presented key issues that should be addressed with the objective of influencing the resilience capacity of Sun City thereby enhancing the social and environmental sustainability of the institution. They were presented as policy recommendations for the Sun City Resort.

Finally, the inter-relationship of the entire complex as place and locality as seen through the 20-30 year club as agents, combined with the establishment of Sun City as the causality, was explored.

\section{Acknowledgements}

Sincerest thanks are presented to the narrators of the life stories playing out in the shadow of the Sun City Resort.
We also thank the directors and management of Sun City Resort and the University of Pretoria for the opportunity to contribute to academic and policy development.

\section{Competing interests}

The authors declare that they have no financial or personal relationship(s) which may have inappropriately influenced them in writing this article.

\section{Authors' contributions}

The article is based on a M.Sc. mini-dissertation by I.S. (University of Pretoria) and supervised by A.C.H. (University of Pretoria).

\section{References}

Barnard, W.S., 1984, 'Gebiede en streke - 'n oorsig van die veranderende plek van gebiedstudie in Geografie', South African Geographer 12, 161-177.

Brida, J.G. \& Zapata, S., 2010, 'Cruise tourism: Economic, socio-cultural and environmental impacts', International Journal of Leisure and Tourism Marketing $1(3), 205-226$

Cloke, P., Philo, C. \& Sadler, D., 1991, Approaching Human Geography: An Introduction to Contemporary Theoretical Debates, Progressive Customer Publishing, London.

Cyber Cape Town, n.d.,'Map of Pilanesberg Game Reserve, Map of Sun City', viewed 13 August 2012, from http://cybercapetown.com/Maps/PilanesbergGameReserve/

Department of Environmental Affairs and Tourism (DEAT), 2002, National Responsible Tourism Development Guidelines for South Africa: Provisional Guidelines, viewed 13 August 2011, from http://www.icrtourism.org/.../Responsible\%20Tourism\%20 Guidelines.doc

Dhunpath, R. \& Samuel, M. (eds.), 2009, Life History Research: Epistemology, Methodology and Representation, Sense Publishers, Rotterdam.

Fraser, H., 2004, Doing Narrative Research: Analysing Personal Stories Line by Line, Sage Publications, London.

Giddens, A., 1984, The Constitution of Society: Outline of the Theory of Structuration, University of California Press, Berkeley, CA.

Global Sustainable Tourism Criteria (GSTC), 2011, Global Sustainable Tourism Criteria: Travel Forever: Global Sustainable Tourism Council, viewed 13 August 2011, from http://new.gstcouncil.org/page/adopt-the-criteria

Holling, C.S., 2001, 'Understanding the complexity of economic, ecological and socia systems', Ecosystems 4, 390-405. http://dx.doi.org/10.1007/s10021-001-0101-5

Lu, J. \& Nepal, S.K., 2009, 'Sustainable tourism research: An analysis of papers published in the Journal of Sustainable Tourism', Journal of Sustainable Tourism 17(1), 5-16. http://dx.doi.org/10.1080/09669580802582480

North West Parks Board, 1997, Pilanesberg: Discovering the Magic: The Complete Ecoguide, Jacana, Johannesburg.

Pandey, R.N., Chettri, P., Kunwar, R.R. \& Ghimire, G., 1995, Case Study on the Effects of Tourism on Culture and the Environment: Nepal; Chitwan-Sauraha and PokharaGhandruk, UNESCO Principal Regional Office for Asia and the Pacific, Bangkok, Thailand. (RACAP Series on Culture and Tourism in Asia 4).

Ricoeur, P., 1992, Oneself as Another, University of Chicago Press, London.

Ringdahl, B., 2003, 'A Political Ecological Analysis of the Pilanesberg National Park and the Lebatlane Tribal Reserve, South Africa', International Master in Environmental Science, Lund University, Lund.

Simpson, M.C., 2007, 'An integrated approach to assess the impacts of tourism on community development and sustainable livelihoods', Community Development Journal, October 17, 1-23.

South African History online: Towards a people's history, 2011, 'Solomon Kerzner', viewed 06 June 2011, from http://www.sahistory.org.za/pages/people/bios/ kerzner_s.html

Spenceley, A. \& Seif, J., 2003, 'Strategies, Impacts and Costs of Pro-Poor Tourism Approaches in South Africa', Pro Poor Tourism Working Paper no 11, viewed 18 April 2011, from http://www.propoortourism.org.uk/11_South_Africa.pdf

Swart, I., 2011a, The Sun City Resort 'The Choice Sustainable Resort', Imvelo Entry 2011, Category Best Social Involvement Programme, Category Best Resource Management: Energy and Category Best Resource Management: Water, available from the Sun City Resort Environmental Office, Sun City.

Swart, I., 2011b, 'Evaluation of the Environmental and Social Sustainability Policy of the Sun City Resort: A Narrative Account', mini-thesis, Centre for Environmental Studies (CFES), University of Pretoria.

Tao, C.H. \& Wall, G., 2008, 'Tourism for Marginal Groups: Tourism as a livelihood Strategy in an Indigenous Community in Taiwan', BESTEN Think Tank VIII, Best Education Network, available from http://www.besteducationnetwork.org 